OPEN ACCESS

Edited by:

Moran Amit,

University of Texas MD Anderson Cancer Center, United States

Reviewed by: Xiao Zhao,

University of Texas MD Anderson Cancer Center, United States

Rania Suliman,

Prince Sultan Military College of

Health, Saudi Arabia

*Correspondence:

Rensheng Wang

13807806008@163.com

Kai Hu

hukaigxmu@163.com

Specialty section: This article was submitted to Head and Neck Cancer, a section of the journal

Frontiers in Oncology

Received: 14 June 2021 Accepted: 11 October 2021 Published: 27 October 2021

Citation:

Wu J, Zhu H, Gao F, Wang R and Hu K (2021) Circulating

Tumor Cells: A Promising Biomarker in the Management of Nasopharyngeal Carcinoma.

Front. Oncol. 11:724150. doi: 10.3389/fonc.2021.724150

\section{Circulating Tumor Cells: A Promising Biomarker in the Management of Nasopharyngeal Carcinoma}

\author{
Jiangtao Wu ${ }^{1}$, Huijun $\mathrm{Zhu}^{2}$, Feifei Gao ${ }^{3}$, Rensheng $\mathrm{Wang}^{1 *}$ and Kai Hu${ }^{1 *}$ \\ ${ }^{1}$ Department of Radiation Oncology, The First Affiliated Hospital of Guangxi Medical University, Nanning, China, \\ 2 Department of Radiation Oncology, The Second Affiliated Hospital of Guangxi Medical University, Nanning, China, \\ ${ }^{3}$ Department of Oncology, Shenzhen Yantian District People's Hospital, Shenzhen, China
}

Nasopharyngeal carcinoma (NPC) is a malignancy that arises from the mucosal epithelium of the nasopharynx, and its prognosis is relatively favorable. The 5-year overall survival rate in patients with locally advanced NPC currently exceeds $80 \%$, but the development of individualized diagnosis and treatment at the molecular level is relatively lacking. Circulating tumor cells (CTCs) is the generic term for tumor cells that are present in the peripheral blood circulation. As a new biomarker with good clinical application prospects, the detection of CTCs has the advantages of being non-invasive, simple, and repeatable. By capturing and detecting CTCs in peripheral blood and monitoring the dynamic variation of its type and quantity, we can assess the biological characteristics of tumor in a timely manner and evaluate the therapeutic effect and prognosis of patients in advance, which will help to develop individualized treatments of tumors. The primary purposes of this review were the clinical application of CTCs in tumor stage determination, treatment efficacy evaluation, and prognosis prediction of NPC. In addition, we estimated the correlation between Epstein-Barr virus infection and CTCs and analyzed the difference in karyotypes and specific markers expressed on CTCs. We believe that our study will provide new insights and biomarkers for the individualized treatment of patients with NPC.

Keywords: circulating tumor cells (CTCs), biomarker (BM), clinical application, individualized treatment, nasopharyngeal carcinoma

\section{INTRODUCTION}

Nasopharyngeal carcinoma (NPC) is a malignancy with regional distribution characteristics that occurs mostly in southern China, Southeast Asia, and Northern Africa (1). Its pathogenesis is related to genetics, diet, environment, and Epstein-Barr virus (EBV) infection (2-4). Recently, with the development of radiotherapy technology and equipment, the 5-year overall survival (OS) of patients with locally advanced NPC has exceeded $80 \%(1,5,6)$, but the development of individualized diagnosis and treatment at the molecular level is relatively lacking. Therefore, identification of accurate and effective biomarkers is key to further improving the therapeutic effect and realizing individualized treatments for patients with NPC.

Circulating tumor cells (CTCs) are tumor cells that are shed from primary or metastatic foci and are present in the peripheral blood (7). Many specific protein markers occur on the surface of CTCs. 
These differentially expressed protein markers are the biological basis for the separation and detection of CTCs in peripheral blood. Epithelial cell adhesion molecules (EpCAMs) and cytokeratins (CKs) are overexpressed in CTCs, and these are specific epithelial markers commonly used to detect CTCs (8). The lack of CD45 expression on the surface and the presence of the nucleus are also characteristic of CTCs. Therefore, CTCs have a characteristic immunophenotype of 'EpCAM+/CK+l CD45-' which exists in the peripheral blood circulation of patients with cancer but not in healthy individuals or patients with non-malignant diseases (9). In recent years, the epithelialmesenchymal transition (EMT) and stem cell-like properties of CTCs have been studied extensively (10). Tumor cells can obtain mesenchymal characterization through EMT such as the loss of cell polarity and adhesion, enhanced cell migration, and intravascular osmotic ability, which leads to the progression and metastasis of malignancy $(11,12)$. According to EMT markers, such as epithelial markers (EpCAMs or CKs) and mesenchymal markers (Vimentin or Twist), CTCs can be divided into three subgroups: epithelial CTCs (only epithelial markers), mesenchymal CTCs (only mesenchymal markers), and hybrid CTCs (both epithelial and mesenchymal markers). Among them, mesenchymal and hybrid CTCs are more aggressive owing to the acquisition of mesenchymal phenotypic characteristics and are often associated with disease progression $(13,14)$. Evidence shows that cancer cells contain abundant cell types and are highly heterogeneous. Cancer stem cells (CSCs) are a subgroup of cancer cells with stem cell properties. CSCs have a strong potential for self-renewal and differentiation which frequently lead to tumor progression, therapy resistance, and distant metastasis $(15,16)$. The presence of stem cell characteristics has been observed in CTCs (17). In ex-vivo cultures of CTCs from patients with colorectal cancer, Grillet et al. (18) reported that CTC lines exhibit hallmarks of CSCs and possess strong metastatic potential. Similar to EMT and stem cell-like properties, which lead to tumor progressions such as invasion and metastasis, CTCs have an important application value in clinical diagnosis, therapeutic effect evaluation, and prognosis prediction of malignancies (Figure 1) .

As one of the main detection targets of liquid biopsy, CTCs have been widely used in many studies, including those involving lung cancer, gastric cancer, breast cancer, and colorectal cancer (19-22). In the past few years, many scholars have conducted extensive research on the application of CTCs in NPC. In this review, we assessed the progress of the clinical application of CTCs and expounded the research status and challenges of CTCs in the diagnosis and treatment of NPC to provide new insights and biomarkers for the realization of individualized diagnosis and treatment of patients with NPC (Figure 2). A summary of the current research on CTCs in NPC is shown in Table $\mathbf{1 .}$

\section{CLINICAL SIGNIFICANCE OF CTCS IN NPC STAGING}

The Tumor-Node-Metastasis (TNM) staging system of the American Joint Committee on Cancer/Union for International Cancer Control is the most widely used staging system worldwide (42). However, with the development of precision medicine, the current staging system which is based on the anatomical structure can no longer meet the needs of individualized treatment. Therefore, many studies have begun to introduce new biomarkers into the staging system for the exploration of individualized treatment (43-45). However, there is no consensus on the relationship between the clinical stages of patients with NPC and the positive rate or number of CTCs.

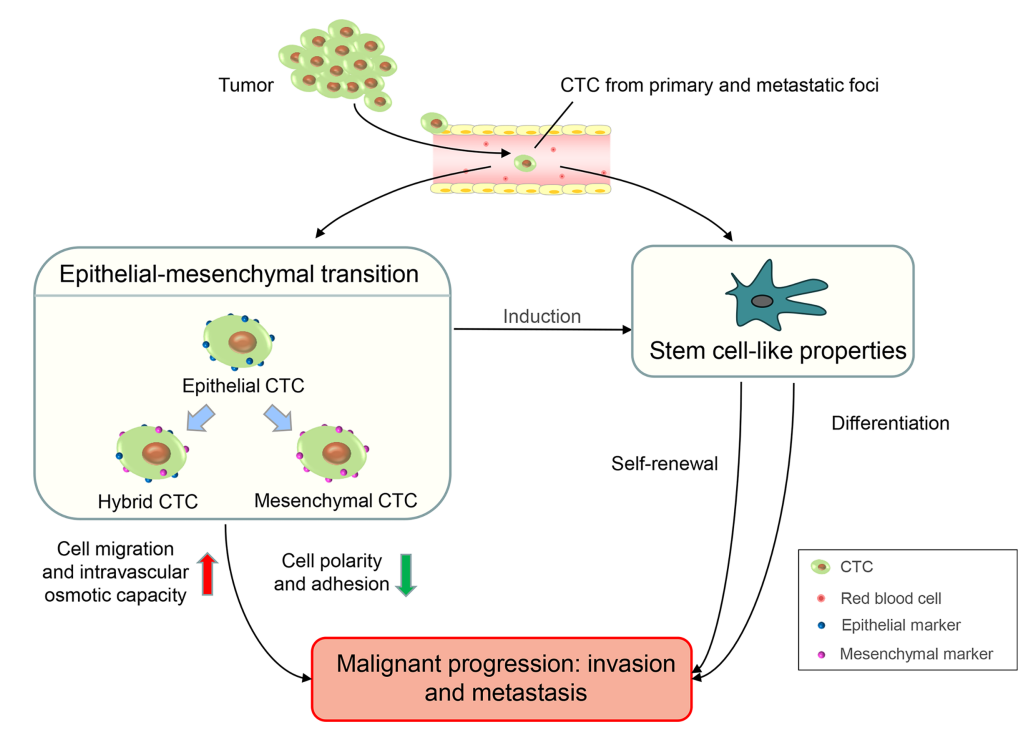

FIGURE 1 | The biological properties of CTCs and their effects on tumors invasion and metastasis. 


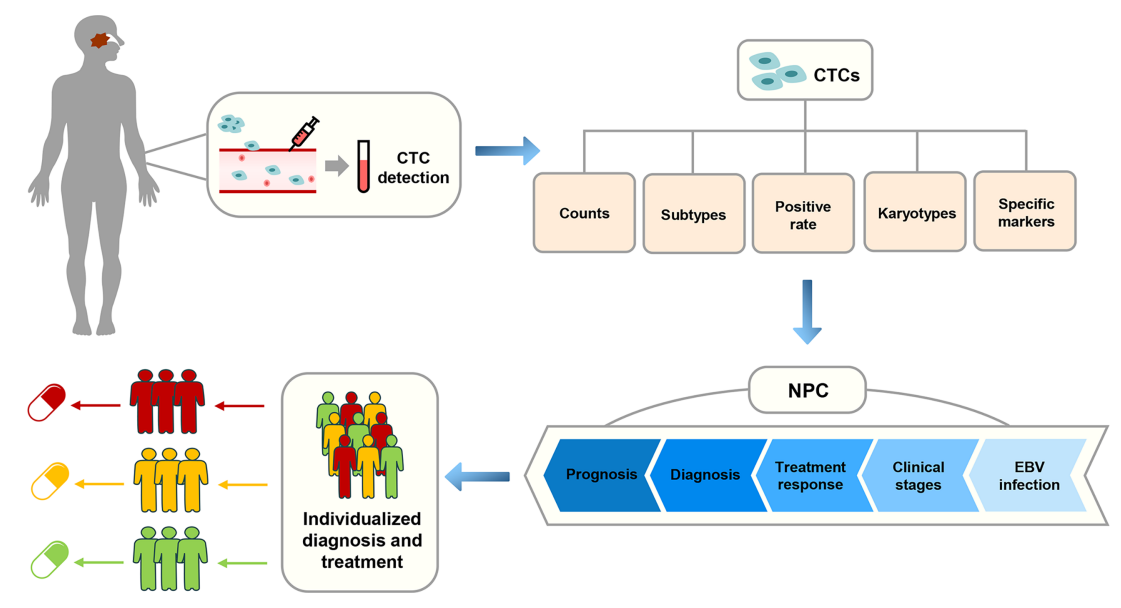

FIGURE 2 | The correlation between the application of CTCs and the individualized diagnosis and treatment of NPC in clinical practice.

By detecting CTCs in 10 healthy volunteers and 50 patients with NPC, Xie et al. (23) found that 48 (96\%) patients with NPC were CTC-positive, but CTCs were not detected in the healthy volunteers. Meanwhile, CTC positivity was related to different NPC clinical stages, and in all the clinical stages, patients with stage IV had the highest mesenchymal CTC positivity. In a retrospective study including 50 patients with NPC, Zhang et al. (24) found that a significant correlation did not exist between the detection rate of CTCs and clinical stage. However, the number of CTCs increased consistently with clinical stage regardless of whether patients were newly diagnosed or had loco-regional recurrence or distant metastasis. In another study of 60 patients with NPC, Wen et al. (25) demonstrated that the positive rates of CTCs in stage II, III, and IV disease were $100 \%, 88.9 \%$, and $83.8 \%$, respectively, and there was no significant association between the positive rate or number of CTCs and TNM stage. However, Zeng et al. (26) found that the positive rate of CTCs was correlated with the N stage of NPC, and CTC-positive patients had a later $\mathrm{N}$ stage. Similarly, Liu et al. (27) reported that the more advanced the clinical stage of patients with NPC, the higher the positive rate of CTCs. Si et al. (28) also showed that there was a significant positive correlation between mesenchymal CTCs and the metastasis of NPC, especially lymph node metastasis. In summary, as one of the main detection targets of liquid biopsy, the positive rate and number of CTCs, along with their relationship with NPC stage, remain controversial and need to be further validated through largescale prospective data.

\section{CTCs IN THE EARLY EVALUATION OF TREATMENT EFFICACY FOR NPC}

Patients with NPC generally choose to evaluate treatment efficacy at 3 months after completing radiotherapy because of the presence of inflammation and oedema of local soft tissues and the sublethal and potentially lethal damage to tumor cells caused by irradiation. However, for some patients who are resistant to radiotherapy, a 3-month waiting time may delay adjuvant therapy. Therefore, researchers have begun to search for more accurate and earlier indicators of treatment efficacy to adjust therapeutic regimens for treatment-resistant NPC patients as early as possible. At present, CTCs are increasingly applied in this field, in addition to the detection of EBV DNA.

A prospective study of locally advanced NPC by Qian et al. (29) found that 27 CTC-positive patients had a significant decrease in CTC count after radiotherapy and chemotherapy. Moreover, compared with patients presenting a partial response $(\mathrm{PR})$, those presenting a complete response (CR) had a significant reduction in CTC count. After comparing the changes in the number of CTCs before and after treatment, Wen et al. (25) found that the number in patients with NPC who achieved CR or PR after treatment often decreased or remained unchanged, while the number in patients with progressive disease (PD) often increased. They also suggested that a posttreatment increase in the number of total and mesenchymal CTCs was often indicative of poor treatment outcomes. Li et al. (30) conducted a retrospective study on 38 patients with NPC. After analyzing the CTCs counts of patients before, 1 week after, and 1 month after radiotherapy, they found that the number of CTCs was significantly reduced at 1 month after radiotherapy. Another study (23) showed that the difference values (i.e., the difference value between the CTC counts before and after treatment) of total CTCs, epithelial CTCs, mesenchymal CTCs, and hybrid CTCs were all greater in NPC patients with CR than in those with PR, stable disease (SD), or PD. Similarly, Zhang et al. (24) found that the CTC count decreased after treatment in patients with $\mathrm{PR}$, while it increased in those with $\mathrm{PD} / \mathrm{SD}$. The aforementioned indicates that the change in CTC counts was related to the therapeutic effect, which could not only provide an important reference for early evaluation of treatment efficacy but also contribute to timely adjuvant therapy for patients with NPC. 
TABLE 1 | Summary of studies on CTCs in nasopharyngeal carcinoma.

\begin{tabular}{|c|c|c|c|c|c|c|c|c|c|c|}
\hline Author & Years & Patients & $\begin{array}{l}\text { CTCs detection } \\
\text { technology }\end{array}$ & $\begin{array}{l}\text { Detection } \\
\text { markers }\end{array}$ & $\begin{array}{l}\text { Specific } \\
\text { markers }\end{array}$ & $\begin{array}{l}\text { Sampling } \\
\text { time }\end{array}$ & $\begin{array}{l}\text { Clinical } \\
\text { stages }\end{array}$ & $\begin{array}{l}\text { Treatment } \\
\text { response }\end{array}$ & Prognosis & Main conclusions \\
\hline Xie et al. (23) & 2019 & 50 & $\begin{array}{l}\text { The CanPatrol } \\
\text { system }\end{array}$ & $\begin{array}{l}\text { CD45, EpCAM, } \\
\text { CK8/18/19, } \\
\text { Vimentin, Twist }\end{array}$ & $\operatorname{cox}-2$ & $\begin{array}{l}\text { Before and } \\
\text { after TM }\end{array}$ & $\sqrt{ }$ & $\sqrt{ }$ & - & $\begin{array}{l}\text { Decreased mesenchymal CTCs and that express COX- } 2 \text { indicated a } \\
\text { favorable therapeutic effect in NPC patients. }\end{array}$ \\
\hline Zhang et al. (24) & 2018 & 50 & SE-iFISH & $\begin{array}{l}\text { CD45, EpCAM, } \\
\text { CEP8, }\end{array}$ & - & $\begin{array}{l}\text { Before and } \\
\text { after TM }\end{array}$ & $\sqrt{ }$ & $\sqrt{ }$ & - & $\begin{array}{l}\text { Real-time monitoring the changes in CTCs number may predict the } \\
\text { chemotherapy efficacy during treatment. Triploid and multiploid CTCs } \\
\text { may related to chemo-resistance. }\end{array}$ \\
\hline Wen et al. (25) & 2019 & 60 & $\begin{array}{l}\text { The CanPatrol } \\
\text { system }\end{array}$ & CD45, CK18, Twist & $\begin{array}{c}\mathrm{N}- \\
\text { cadherin }\end{array}$ & $\begin{array}{l}\text { Before and } \\
\text { after TM }\end{array}$ & $\sqrt{ }$ & $\sqrt{ }$ & $\sqrt{ }$ & $\begin{array}{l}\text { The increased number of total and mesenchymal CTCs after } \\
\text { treatment indicated poor therapeutic effects. Mesenchymal CTCs may } \\
\text { serve as a predictor of PFS. }\end{array}$ \\
\hline Zeng et al. (26) & 2019 & 60 & $\begin{array}{l}\text { The Cyttel } \\
\text { detection }\end{array}$ & CD45, CEP8 & - & $\begin{array}{l}\text { Before and } \\
\text { after TM }\end{array}$ & $\sqrt{ }$ & $\sqrt{ }$ & $\sqrt{ }$ & Patients with CTCs positive had a later $\mathrm{N}$ stage and a shorter OS. \\
\hline Liu et al. (27) & 2020 & 135 & $\begin{array}{l}\text { The Cyttel } \\
\text { detection }\end{array}$ & CD45, CEP8 & - & $\begin{array}{l}\text { Before and } \\
\text { after TM }\end{array}$ & $\sqrt{ }$ & - & $\sqrt{ }$ & $\begin{array}{l}\text { After treatment, CTCs-positive patients' PFS and OS were } \\
\text { significantly lower than those in CTCs-negative patients. }\end{array}$ \\
\hline Si et al. (28) & 2016 & 81 & $\begin{array}{l}\text { The CanPatrol } \\
\text { system }\end{array}$ & CD45, CK19, Twist & MMP9 & $\begin{array}{l}\text { Before and } \\
\text { after TM }\end{array}$ & $\sqrt{ }$ & $\sqrt{ }$ & - & $\begin{array}{l}\text { Decreased CTCs in NPC patients indicated a favourable therapeutic } \\
\text { effect. Hybrid and mesenchymal CTCs were significantly correlated } \\
\text { with metastasis. MMP9 existed in CTCs and expressed most in } \\
\text { mesenchymal CTCs. }\end{array}$ \\
\hline Qian et al. (29) & 2019 & 50 & $\begin{array}{l}\text { The Cyttel } \\
\text { detection }\end{array}$ & CD45, CEP8 & - & $\begin{array}{l}\text { Before and } \\
\text { after TM }\end{array}$ & $\sqrt{ }$ & $\sqrt{ }$ & - & $\begin{array}{l}\text { The decrease in CTCs number during chemotherapy and } \\
\text { radiotherapy suggested a favourable therapeutic effect. }\end{array}$ \\
\hline Li et al. (30) & 2016 & 38 & $\begin{array}{l}\text { The Cyttel } \\
\text { detection }\end{array}$ & CD45, CEP8 & - & $\begin{array}{l}\text { Before and } \\
\text { after TM }\end{array}$ & $\sqrt{ }$ & $\sqrt{ }$ & - & $\begin{array}{l}\text { There was no statistically significant correlation between CTC number } \\
\text { or positivity and clinical parameters like TNM stages, but CTCs } \\
\text { number was remarkably decreased after radiotherapy. }\end{array}$ \\
\hline Ou et al. (31) & 2019 & 370 & $\begin{array}{l}\text { The CellSearch }{ }^{\circledR} \\
\text { system }\end{array}$ & $\begin{array}{l}\text { CD45, EpCAM, } \\
\text { CK8/18/19 }\end{array}$ & - & $\begin{array}{l}\text { Before and } \\
\text { after TM }\end{array}$ & $\sqrt{ }$ & - & $\sqrt{ }$ & $\begin{array}{l}\text { The more CTCs count, the worse prognosis in patients with } \\
\text { advanced NPC. }\end{array}$ \\
\hline Wu et al. (32) & 2017 & 67 & $\begin{array}{l}\text { Antibody labeling } \\
\text { and flow cytometry }\end{array}$ & CD45, EpCAM, CK & - & Before TM & $\sqrt{ }$ & - & $\sqrt{ }$ & $\begin{array}{l}\text { Positive CTCs in peripheral blood was associated with N staging and } \\
\text { indicated a poor prognosis in NPC patients. }\end{array}$ \\
\hline Cai et al. (33) & 2011 & 76 & IME-FICC & EpCAM, CK8/18 & - & Before TM & - & - & $\sqrt{ }$ & $\begin{array}{l}\text { CTCs' positive rate was associated with recurrence-free survival and } \\
\text { overall survival. }\end{array}$ \\
\hline Li et al. (34) & 2018 & 131 & $\begin{array}{l}\text { The CanPatrol } \\
\text { system }\end{array}$ & $\begin{array}{l}\text { CD45, EpCAM, } \\
\text { CK8/18/19, } \\
\text { Vimentin, Twist }\end{array}$ & cox-2 & $\begin{array}{l}\text { Before and } \\
\text { after TM }\end{array}$ & $\sqrt{ }$ & $\sqrt{ }$ & $\sqrt{ }$ & $\begin{array}{l}\text { The COX-2 expression on CTCs after treatment was associated with } \\
\text { poor therapeutic effect and the high risk of recurrence and } \\
\text { metastasis. }\end{array}$ \\
\hline Yu et al. (35) & 2020 & 179 & $\begin{array}{l}\text { The CanPatrol } \\
\text { system }\end{array}$ & $\begin{array}{l}\text { CD45, EpCAM, } \\
\text { CK8/18/19, } \\
\text { Vimentin, Twist }\end{array}$ & FN1 & $\begin{array}{l}\text { Before and } \\
\text { after TM }\end{array}$ & $\sqrt{ }$ & - & $\sqrt{ }$ & $\begin{array}{l}\text { NPC patients with high expression of FN } 1 \text { on CTCs had a poor } \\
\text { prognosis. }\end{array}$ \\
\hline Fu et al. (36) & 2017 & 33 & qRT-PCR & - & $\begin{array}{l}\text { hTERT } \\
\text { mRNA }\end{array}$ & $\begin{array}{l}\text { Before and } \\
\text { after TM }\end{array}$ & $\sqrt{ }$ & $\sqrt{ }$ & - & $\begin{array}{l}\text { Radiochemotherapy can effectively reduce the hTERT mRNA levels in } \\
\text { peripheral blood and CTCs of NPC patients. Combined detection of } \\
\text { hTERT mRNA levels and CTCs in peripheral blood can become a new } \\
\text { biomarker for therapeutic effect and prognosis of NPC. }\end{array}$ \\
\hline He et al. (37) & 2017 & 33 & $\begin{array}{l}\text { ISET and IHC } \\
\text { staining }\end{array}$ & CK5/6, P63 & - & $\begin{array}{l}\text { Before and } \\
\text { after TM }\end{array}$ & $\sqrt{ }$ & - & - & $\begin{array}{l}\text { There was a positive correlation between CTCs and EBV activation in } \\
\text { NPC patients. }\end{array}$ \\
\hline Wu et al. (38) & 2015 & 63 & $\begin{array}{l}\text { The Cyttel }{ }^{\mathrm{TM}} \text { CTC } \\
\text { detection }\end{array}$ & CD45, CEP8 & - & Before TM & $\sqrt{ }$ & - & - & CTCs were closely related to NPC metastasis and EBV-DNA. \\
\hline Mao et al. (39) & 2019 & 49 & $\begin{array}{l}\text { The CanPatrol }{ }^{\mathrm{TM}} \\
\text { system }\end{array}$ & $\begin{array}{l}\text { CD45, EpCAM, } \\
\text { CK8/18/19, } \\
\text { Vimentin, Twist }\end{array}$ & - & Before TM & $\sqrt{ }$ & - & - & $\begin{array}{l}\text { CTCs were correlated with systemic metastasis and EBV DNA in NPC } \\
\text { patients. }\end{array}$ \\
\hline
\end{tabular}




\section{CLINICAL SIGNIFICANCE OF CTCs IN THE PROGNOSIS OF NPC}

CTCs are malignant cells that detach from primary or metastatic foci and enter blood vessels, and they can spread to distant organs through peripheral blood circulation and develop into possible metastatic foci $(7,46)$. Their number is recognized to be associated with tumor burden. As a target of real-time liquid biopsy, CTCs have also increasingly been identified as a potential biomarker to assess the biological characteristics of tumors and predict the prognosis of patients. Accordingly, they have attracted attention in clinical practice.

In a retrospective study involving 370 patients with NPC, Ou et al. (31) confirmed that CTC count was an independent risk factor for poor outcomes by using sex, age, EBV DNA, and CTC count as variables in the Cox regression model. In particular, for patients with advanced NPC (70 cases of stage III and 288 cases of stage IV), the Kaplan-Meier survival analysis revealed that a higher CTC count was associated with a worse prognosis. Wen et al. (25) reported that mesenchymal CTCs could be used as a predictor of progression-free survival (PFS) in patients with NPC. Among 36 patients treated with cisplatin and paclitaxel, mesenchymal CTCs were significantly associated with PFS following therapy, and the PFS of patients who were mesenchymal CTC-negative was notably better than that of mesenchymal CTC-positive patients. Wu et al. (32) analyzed the survival of 67 patients with NPC and showed that the 3-year OS and PFS rates were significantly better in the CTC-negative group ( $100 \%$ and $85.7 \%$, respectively) than in the CTC-positive group (92.9\% and $73.7 \%$, respectively). Cai et al. (33) indicated that CTC-positive NPC patients had shorter OS and lower relapse-free survival rates than CTC-negative NPC patients. This result was consistent with the findings reported by Liu et al. (27), in which patients with NPC with elevated CTC counts had significantly lower PFS than those with decreased or unchanged CTC counts after treatment. Si et al. (28) also showed that decreased CTC counts after treatment suggested a favorable therapeutic effect in patients with NPC. Therefore, CTC count has the potential to predict the prognosis of patients with NPC, and CTC positivity is often associated with poor prognosis.

\section{CLINICAL APPLICATION OF CTC KARYOTYPING IN NPC}

Nearly all mammals are diploid, whereas most human solid tumors are aneuploid and range from hypodiploid to hypertetraploid. Abnormal chromosomes are considered to be a vital factor for tumorigenesis (47). With the development of immunofluorescence in situ hybridization and chromosome probes, karyotypic analysis of CTCs can now be performed conveniently (48). Karyotypic analysis of chromosome 8 ploidy is the most well-developed and widely used method $(49,50)$.

CTC karyotypic analysis upon ploidy of chromosome 8 in 50 patients with NPC by Zhang et al. (24) revealed that the ratio of 
triploid CTCs was the highest compared with other karyotypes in newly diagnosed patients (M0), while the number of polyploid CTCs was the largest in those with recurrence or distant metastasis. However, there was no significant correlation between CTC count and different karyotypes and TNM stage. Their study also indicated that the ploidy of chromosome 8 in CTCs was associated with the efficacy of chemotherapy. In comparison, the tetraploid CTC count was decreased to a greater extent than both triploid and multiploidy CTC counts after chemotherapy with gemcitabine plus cisplatin. Specifically, the proportion of tetraploid CTCs was significantly decreased in all patients. Nevertheless, the ratio of triploid and multiploid CTCs all showed only a slight decline in PR patients after treatment. Moreover, for $\mathrm{PD} / \mathrm{SD}$ patients, the frequency of triploid CTCs was increased from $66.7 \%$ to $100 \%$, and multiploid CTCs remained the same after treatment. Similarly, a study performed by Qian et al. (29), showed that, after chemoradiotherapy, different karyotypes of CTCs were all significantly decreased in patients with NPC with CR, whereas statistical significance was not reached in those without CR. Their results also indicated that fewer tetraploid CTCs were correlated with CR in patients with locally advanced NPC. Notably, these studies suggested that CTC karyotyping is related to treatment response and can be used as a new biomarker for the prediction of chemoradiotherapy sensitivity and treatment efficacy.

\section{RESEARCH PROGRESS OF SPECIFIC MARKERS ON CTCs IN NPC}

CTCs are considered to be 'miniature' versions of primary tumors which exist in peripheral blood circulation, and the expression of phenotypic and genetic markers on CTCs can reflect the biological characteristics of primary tumors. At present, the detection of specific markers on CTCs is an important breakthrough in studying the biological behavior of primary tumors and guiding clinical diagnosis and treatment.

Cyclooxygenase-2 (COX-2) is an inducible enzyme involved in cell proliferation and tumor angiogenesis and plays a pivotal role in tumor genesis and development (51). A prospective study by $\mathrm{Li}$ et al. (34) stated that COX-2 can be expressed on the CTCs of patients with NPC before and after treatment. COX-2 expression on CTCs after treatment was markedly associated with poor treatment response and a high risk of tumor recurrence and metastasis and can thus be used as an independent prognostic indicator for poorer OS and PFS. Xie et al. (23) found that the positivity of COX-2 on CTCs was higher in patients with NPC with stage IV than in those with stage II and III. Moreover, the decline of mesenchymal CTCs which express COX-2 was related to a favorable therapeutic effect for NPC.

Matrix metalloproteinase 9 (MMP-9) is a zinc-containing endopeptidase that participates in the degradation of the extracellular matrix and vascular reconstruction and is associated with tumor invasiveness and progression (52-54). Si et al. (28) confirmed that MMP-9 could be expressed in different types of CTCs in NPC and was mostly expressed in mesenchymal CTCs. However, there were no correlations between MMP-9 and clinical stage, EBV, and other characteristics like smoking in patients with NPC. Interestingly, Liu et al. (55) found that the overexpression of MMP-9 was associated with poor prognosis in patients with NPC.

$\mathrm{N}$-cadherin is a Ca2+-dependent cellular adhesion molecule that is closely related to EMT, and its expression plays a prominent role in tumor invasion and metastasis (56-58). Wen et al. (25) indicated that N-cadherin can be expressed in epithelial, mesenchymal, and hybrid CTCs, but its overexpression was rare in all three types. The relationship between $\mathrm{N}$-cadherin expression on CTCs and clinical parameters of NPC should be studied further.

Fibronectin 1 (FN1) is an important extracellular matrix molecule that plays an important role in cell adhesion, migration, and carcinogenesis (59). Yu et al. (35) found that FN1 expression on CTCs was correlated with the clinical stages of NPC, and patients with stage IV had the highest number of CTCs expressing FN1. Furthermore, it has been suggested that FN1 overexpression on CTCs is often associated with poor survival in patients with NPC.

Hence, combining the detection of specific surface markers on CTCs with clinical characteristics may be a new direction to guide clinical decision-making and realize individualized treatment for malignancy in the future. Besides the specific markers on CTCs, the transcriptome of CTCs has also been studied. Fu et al. (36) found that increased human telomerase reverse transcription (hTERT) mRNA levels in CTCs and peripheral blood of patients with NPC were closely related to the later clinical stage. Moreover, chemoradiotherapy was an effective method to reduce hTERT mRNA levels in CTCs and peripheral blood. Nevertheless, studies focusing on the transcriptome of CTCs are still limited.

\section{RELATIONSHIP BETWEEN CTCs AND EBV DNA IN NPC}

NPC is invariably associated with EBV infection (60). Circulating cell-free EBV DNA consisting of short DNA fragments released by NPC cells can be detected using ultrasensitive polymerase chain reaction-based assays $(3,61)$. Therefore, the detection of this biomarker presents an important clinical application in population screening, risk stratification, efficacy monitoring, and prognosis prediction in patients with $\operatorname{NPC}(62,63)$. Recently, some studies have found that the coding products of EBV can promote the generation of CTCs (64), and the combined application of EBV and CTCs has become a hotspot in the diagnosis and treatment of NPC.

He et al. (37) found that serum EBV capsid antigen IgA (EBV VCA-IgA) levels in CTC-positive NPC patients were higher than those in CTC-negative NPC patients, and CTC enumeration was positively correlated with the EBV DNA load and EBV VCA-IgA levels. A study conducted by Wu et al. (38) involving 63 patients with NPC revealed that the positive rate of CTCs was notably 
correlated with the EBV DNA status, and it was significantly lower in EBV DNA-negative patients than in EBV DNA-positive patients. Moreover, Mao et al. (39) came to similar conclusions. Xie et al. (23) reported that EBV DNA-positive NPC patients had both a higher proportion of mesenchymal CTCs and expression of COX-2 than EBV DNA-negative patients. Thus, CTCs and COX2 expression are associated with EBV DNA in patients with NPC; however, the mechanisms remain unclear. Interestingly, Vo et al. (40) found that there was no significant correlation between CTC counts and EBV DNA levels, and this may be due to the different CTC detection techniques which need to be studied further.

A prospective cohort study of metastatic NPC performed by You et al. (41) found that the variations between CTC counts and EBV DNA copies at baseline and after first-line chemotherapy were important independent prognostic factors for PFS and OS, respectively. Furthermore, they suggested that CTC count had superior specificity but inferior sensitivity when compared with plasma EBV DNA copies in the diagnosis of distant metastasis of NPC. Therefore, the combination of CTCs and EBV DNA was a stronger predictive marker than a single indicator, and when utilized in conjunction with imaging, it could provide additional information for individual diagnosis and treatment of NPC.

\section{CIRCULATING TUMOR CELL MICROEMBOLI IN NPC}

The CTC cluster is composed of two or more tumor cells, also known as circulating tumor cell microemboli (CTM), which has 23-50 times the metastatic potential compared with a single CTC for cancer patients (65). Although CTM can be detected in the peripheral blood of patients with cancer, the number is relatively low. Among the known studies about CTCs in NPC, CTM was only detected in the study of $\mathrm{He}$ et al. (37) and Zhang et al. (24) with a detection rate of $6 \%(2 / 33)$ and $12 \%(6 / 50)$, respectively. However, the clinical significance of CTM was not clarified for patients with NPC in the two studies. Thus, the mechanism of CTM metastasis and its clinical value for NPC still need to be explored further.

\section{CONCLUSION}

With the development of liquid biopsy techniques, CTCs, as a potential new biomarker, have an important clinical application value in determining the clinical stage, evaluating treatment

\section{REFERENCES}

1. Chen Y-P, Chan ATC, Le Q-T, Blanchard P, Sun Y, Ma J. Nasopharyngeal Carcinoma. Lancet (2019) 394(10192):64-80. doi: 10.1016/S0140-6736(19)30956-0

2. Tsao SW, Yip YL, Tsang CM, Pang PS, Lau VMY, Zhang G, et al. Etiological Factors of Nasopharyngeal Carcinoma. Oral Oncol (2014) 50(5):330-8. doi: 10.1016/j.oraloncology.2014.02.006

3. Lin J-C, Wang W-Y, Chen KY, Wei Y-H, Liang W-M, Jan J-S, et al. Quantification of Plasma Epstein-Barr Virus DNA in Patients With efficacy, and predicting the prognosis of NPC. Meanwhile, different karyotypes and specific markers expressed on CTCs in patients with NPC can provide further information regarding chemoradiotherapy sensitivity and treatment response. Thus, CTCs would be a good addition to the existing TNM staging system based on the anatomical structure; furthermore, it could be advantageous in providing better individualized treatments for patients with NPC.

However, the current clinical application of CTCs in NPC still presents many limitations. Most reported studies are retrospective analyses with a small samples size, and the technical methods for CTC detection vary, leading to inconsistent results. Meanwhile, there are many challenges in current research, such as the marked inter- and intra-patient heterogeneity of the phenotypic and genetic markers on CTCs. Therefore, considering a unified and standardized detection technology, searching for new CTC-specific markers, and performing prospective large-scale clinical research are promising ways for CTC detection to be widely applied in clinical practice and to further achieve individualized treatments for patients with NPC in the future.

\section{AUTHOR CONTRIBUTIONS}

RW and $\mathrm{KH}$ designed and revised the manuscript and participated in the literature analysis. JW and $\mathrm{KH}$ searched the literature, wrote the manuscript, and created the figures and tables. JW, HZ, and FG coordinated, edited, and finalized the drafting of the manuscript. All authors contributed to the article and approved the submitted version.

\section{FUNDING}

This work was supported by grants from the National Natural Science Foundation of China (No. 82060019), the Natural Science Foundation of Guangxi (2018JJA140869), and the Guangxi Medical and Health Appropriate Technology Development and Application Project (S2018097).

\section{ACKNOWLEDGMENTS}

We would like to thank Editage (www.editage.cn) for English language editing.

Advanced Nasopharyngeal Carcinoma. N Engl J Med (2004) 350(24):246170. doi: 10.1056/NEJMoa032260

4. Tsao SW, Tsang CM, Lo KW. Epstein-Barr Virus Infection and Nasopharyngeal Carcinoma. Philos Trans R Soc Lond B Biol Sci (2017) 372 (1732):20160270. doi: 10.1098/rstb.2016.0270

5. Blanchard P, Lee A, Marguet S, Leclercq J, Ng WT, Ma J, et al. Chemotherapy and Radiotherapy in Nasopharyngeal Carcinoma: An Update of the MACNPC Meta-Analysis. Lancet Oncol (2015) 16(6):645-55. doi: 10.1016/S14702045(15)70126-9 
6. Chen L, Hu C-S, Chen X-Z, Hu G-Q, Cheng Z-B, Sun Y, et al. Adjuvant Chemotherapy in Patients With Locoregionally Advanced Nasopharyngeal Carcinoma: Long-Term Results of a Phase 3 Multicentre Randomised Controlled Trial. Eur J Cancer (Oxford Engl 1990) (2017) 75:150-8. doi: 10.1016/j.ejca.2017.01.002

7. Williams SCP. Circulating Tumor Cells. Proc Natl Acad Sci USA (2013) 110 (13):4861. doi: $10.1073 /$ pnas.1304186110

8. Mavroudis D. Circulating cancer cells. Ann Oncol (2010) 21 Suppl 7:vii95100. doi: 10.1093/annonc/mdq378

9. Allard WJ, Matera J, Miller MC, Repollet M, Connelly MC, Rao C, et al. Tumor Cells Circulate in the Peripheral Blood of All Major Carcinomas But Not in Healthy Subjects or Patients With Nonmalignant Diseases. Clin Cancer Res (2004) 10(20):6897-904. doi: 10.1158/1078-0432.CCR-04-0378

10. Werner S, Stenzl A, Pantel K, Todenhöfer T. Expression of Epithelial Mesenchymal Transition and Cancer Stem Cell Markers in Circulating Tumor Cells. Adv Exp Med Biol (2017) 994:205-28. doi: 10.1007/978-3319-55947-6_11

11. Nieto MA, Huang RY-J, Jackson RA, Thiery JP. EMT: 2016. Cell (2016) 166 (1):21-45. doi: 10.1016/j.cell.2016.06.028

12. Pastushenko I, Brisebarre A, Sifrim A, Fioramonti M, Revenco T, Boumahdi S, et al. Identification of the Tumour Transition States Occurring During EMT. Nature (2018) 556(7702):463-8. doi: 10.1038/s41586-018-0040-3

13. Yu M, Bardia A, Wittner BS, Stott SL, Smas ME, Ting DT, et al. Circulating Breast Tumor Cells Exhibit Dynamic Changes in Epithelial and Mesenchymal Composition. Science (2013) 339(6119):580-4. doi: 10.1126/science.1228522

14. Wu S, Liu S, Liu Z, Huang J, Pu X, Li J, et al. Classification of Circulating Tumor Cells by Epithelial-Mesenchymal Transition Markers. PLoS One (2015) 10(4):e0123976. doi: 10.1371/journal.pone.0123976

15. Lytle NK, Barber AG, Reya T. Stem Cell Fate in Cancer Growth, Progression and Therapy Resistance. Nat Rev Cancer (2018) 18(11):669-80. doi: 10.1038/ s41568-018-0056-x

16. Reya T, Morrison SJ, Clarke MF, Weissman IL. Stem Cells, Cancer, and Cancer Stem Cells. Nature (2001) 414(6859):105-11. doi: 10.1038/35102167

17. Tinhofer I, Saki M, Niehr F, Keilholz U, Budach V. Cancer Stem Cell Characteristics of Circulating Tumor Cells. Int J Radiat Biol (2014) 90 (8):622-7. doi: 10.3109/09553002.2014.886798

18. Grillet F, Bayet E, Villeronce O, Zappia L, Lagerqvist EL, Lunke S, et al. Circulating Tumour Cells From Patients With Colorectal Cancer Have Cancer Stem Cell Hallmarks in Ex Vivo Culture. Gut (2017) 66(10):1802-10. doi: 10.1136/gutjnl-2016-311447

19. Lee C-H, Hsieh JC-H, Wu TM-H, Yeh T-S, Wang H-M, Lin Y-C, et al. Baseline Circulating Stem-Like Cells Predict Survival in Patients With Metastatic Breast Cancer. BMC Cancer (2019) 19(1):1167. doi: 10.1186/ s12885-019-6370-1

20. Tanaka F, Yoneda K, Kondo N, Hashimoto M, Takuwa T, Matsumoto S, et al. Circulating Tumor Cell as a Diagnostic Marker in Primary Lung Cancer. Clin Cancer Res (2009) 15(22):6980-6. doi: 10.1158/1078-0432.CCR-09-1095

21. Yang C, Zou K, Yuan Z, Guo T, Xiong B. Prognostic Value of Circulating Tumor Cells Detected With the CellSearch System in Patients With Gastric Cancer: Evidence From a Meta-Analysis. Onco Targets Ther (2018) 11:101323. doi: 10.2147/OTT.S154114

22. Goodman CR, Seagle B-LL, Friedl TWP, Rack B, Lato K, Fink V, et al. Association of Circulating Tumor Cell Status With Benefit of Radiotherapy and Survival in Early-Stage Breast Cancer. JAMA Oncol (2018) 4(8):e180163. doi: 10.1001/jamaoncol.2018.0163

23. Xie XQ, Luo Y, Ma XL, Li SS, Liu L, Zhang H, et al. Clinical Significance of Circulating Tumor Cells and Their Expression of Cyclooxygenase-2 in Patients With Nasopharyngeal Carcinoma. Eur Rev Med Pharmacol Sci (2019) 23(16):6951-61. doi: 10.26355/eurrev_201908_18735

24. Zhang J, Shi H, Jiang T, Liu Z, Lin PP, Chen N. Circulating Tumor Cells With Karyotyping as a Novel Biomarker for Diagnosis and Treatment of Nasopharyngeal Carcinoma. BMC Cancer (2018) 18(1):1133. doi: 10.1186/ s12885-018-5034-x

25. Wen Z, Li Z, Yong P, Liang D, Xie D, Chen H, et al. Detection and Clinical Significance of Circulating Tumor Cells in Patients With Nasopharyngeal Carcinoma. Oncol Lett (2019) 18(3):2537-47. doi: 10.3892/ol.2019.10560

26. Zeng W, Li W, Zou G, Cao X, He Y, Li J, et al. Role of Peripheral Blood Circulating Tumor Cells and Their Changes in the Evaluation of Curative
Effect and Prognosis of Locally Advanced Nasopharyngeal Carcinoma. Med Innovation China (2019) 16(32):134-8. doi: 10.3969/j.issn.16744985.2019.32.035

27. Liu K, Chen N, Wei J, Ma L, Yang S, Zhang X. Clinical Significance of Circulating Tumor Cells in Patients With Locally Advanced Head and Neck Squamous Cell Carcinoma. Oncol Rep (2020) 43(5):1525-35. doi: 10.3892/ or.2020.7536

28. Si Y, Lan G, Deng Z, Wang Y, Lu Y, Qin Y, et al. Distribution and Clinical Significance of Circulating Tumor Cells in Nasopharyngeal Carcinoma. Jpn J Clin Oncol (2016) 46(7):622-30. doi: 10.1093/jjco/hyw046

29. Qian Y, Wu Y, Yuan Z, Niu X, He Y, Peng J, et al. The Frequency of Circulating Tumour Cells and the Correlation With the Clinical Response to Standard Chemoradiotherapy in Locally Advanced Nasopharyngeal Carcinoma: A Prospective Study. Cancer Manage Res (2019) 11:10187-93. doi: 10.2147/CMAR.S222916

30. Li F, Liu J, Song D, Zhang Q, Ding N, He X. Circulating Tumor Cells in the Blood of Poorly Differentiated Nasal Squamous Cell Carcinoma Patients: Correlation With Treatment Response. Acta Oto-Laryngologica (2016) 136 (11):1164-7. doi: 10.1080/00016489.2016.1201861

31. Ou G, Xing S, Li J, Zhang L, Chen S. Circulating Tumor Cells: A Valuable Marker of Poor Prognosis for Advanced Nasopharyngeal Carcinoma. Mol Med (Cambridge Mass) (2019) 25(1):50. doi: 10.1186/ s10020-019-0112-3

32. Wu J, He J, Du K, Yuan J, Dong Y, Peng Q, et al. Detection of Circulating Tumor Cells in Peripheral Blood of Patients With Nasopharyngeal Carcinoma and Evaluate Its Prognostic Value. Modern Oncol (2017) 25(07):1035-9. doi: 10.3969/j.issn.1672-4992.2017.07.010

33. Cai Q, Ding Y, Lin T, Huang H. Detection and Clinical Significance of Circulating Tumor Cells in Peripheral Blood of Nasopharyngeal Cancer Patients With Modified Immunomagnetic Enrichment and Fluorescent Immunocytochemistry. Chin J Pathophysiol (2011) 27(10):1896-901. doi: 10.3969/j.issn.1000-4718.2011.10.008

34. Li Y-J, Luo Y, Xie X-Q, Li P, Wang F. The Prognostic Value of COX-2 Expression on Circulating Tumor Cells in Nasopharyngeal Carcinoma: A Prospective Analysis. Radiother Oncol J Eur Soc Ther Radiol Oncol (2018) 129 (2):396-402. doi: 10.1016/j.radonc.2018.07.022

35. Yu Y, Lin Z-X, Li H-W, Luo H-Q, Yang D-H, Zhou H-C, et al. Circulating Tumor Cells and Fibronectin 1 in the Prognosis of Nasopharyngeal Carcinoma. Technol Cancer Res Treat (2020) 19:1533033820909911. doi: 10.1177/1533033820909911

36. Fu X, Shen C, Wang H, Chen F, Li G, Wen Z. Joint Quantitative Measurement of hTERT mRNA in Both Peripheral Blood and Circulating Tumor Cells of Patients With Nasopharyngeal Carcinoma and Its Clinical Significance. BMC Cancer (2017) 17(1):479. doi: 10.1186/s12885-017-3471-6

37. He C, Huang X, Su X, Tang T, Zhang X, Ma J, et al. The Association Between Circulating Tumor Cells and Epstein-Barr Virus Activation in Patients With Nasopharyngeal Carcinoma. Cancer Biol Ther (2017) 18(11):888-94. doi: 10.1080/15384047.2017.1281493

38. Wu Y, Weng C, Fang X, Cao X, Li B, Mao H, et al. Correlation of Circulating Tumor Cells With Clinicopathological Parameters in Patients With Nasopharyngeal Carcinoma. China Med Pharmacy (2015) 5(09):17-9+98. doi: CNKI:SUN:GYKX.0.2015-09-006

39. Yan-jiao M, Jian-feng X, Wei Y. Expression of Circulating Tumor Cells in Peripheral Blood of 49 Cases With Nasopharyngeal Carcinoma. J Chin Oncol (2019) 25(02):97-101. doi: 10.11735/j.issn.1671-170X.2019.02.B005

40. Vo JH, Nei WL, Hu M, Phyo WM, Wang F, Fong KW, et al. Comparison of Circulating Tumour Cells and Circulating Cell-Free Epstein-Barr Virus DNA in Patients With Nasopharyngeal Carcinoma Undergoing Radiotherapy. Sci Rep (2016) 6(1):13. doi: 10.1038/s41598-016-0006-3

41. You R, Liu Y-P, Lin M, Huang P-Y, Tang L-Q, Zhang Y-N, et al. Relationship of Circulating Tumor Cells and Epstein-Barr Virus DNA to Progression-Free Survival and Overall Survival in Metastatic Nasopharyngeal Carcinoma Patients. Int J Cancer (2019) 145(10):2873-83. doi: 10.1002/ijc.32380

42. Amin MB, Greene FL, Edge SB, Compton CC, Gershenwald JE, Brookland RK, et al. The Eighth Edition AJCC Cancer Staging Manual: Continuing to Build a Bridge From a Population-Based to a More "Personalized" Approach to Cancer Staging. CA Cancer J Clin (2017) 67(2):93-9. doi: 10.3322/ caac. 21388 
43. Cho WC-S. Nasopharyngeal Carcinoma: Molecular Biomarker Discovery and Progress. Mol Cancer (2007) 6:1. doi: 10.1186/1476-4598-6-1

44. Kang H, Kiess A, Chung CH. Emerging Biomarkers in Head and Neck Cancer in the Era of Genomics. Nat Rev Clin Oncol (2015) 12(1):11-26. doi: 10.1038/ nrclinonc. 2014.192

45. Janvilisri T. Omics-Based Identification of Biomarkers for Nasopharyngeal Carcinoma. Dis Markers (2015) 2015:762128. doi: 10.1155/2015/762128

46. Masuda T, Hayashi N, Iguchi T, Ito S, Eguchi H, Mimori K. Clinical and Biological Significance of Circulating Tumor Cells in Cancer. Mol Oncol (2016) 10(3):408-17. doi: 10.1016/j.molonc.2016.01.010

47. Davoli T, de Lange T. The Causes and Consequences of Polyploidy in Normal Development and Cancer. Annu Rev Cell Dev Biol (2011) 27:585-610. doi: 10.1146/annurev-cellbio-092910-154234

48. Swennenhuis JF, Tibbe AGJ, Levink R, Sipkema RCJ, Terstappen LWMM. Characterization of Circulating Tumor Cells by Fluorescence In Situ Hybridization. Cytometry A (2009) 75(6):520-7. doi: 10.1002/cyto.a.20718

49. Li Y, Zhang X, Ge S, Gao J, Gong J, Lu M, et al. Clinical Significance of Phenotyping and Karyotyping of Circulating Tumor Cells in Patients With Advanced Gastric Cancer. Oncotarget (2014) 5(16):6594-602. doi: 10.18632/ oncotarget.2175

50. Wang L, Li Y, Xu J, Zhang A, Wang X, Tang R, et al. Quantified Postsurgical Small Cell Size CTCs and EpCAM Circulating Tumor Stem Cells With Cytogenetic Abnormalities in Hepatocellular Carcinoma Patients Determine Cancer Relapse. Cancer Lett (2018) 412:99-107. doi: 10.1016/j.canlet. 2017.10.004

51. Greenhough A, Smartt HJM, Moore AE, Roberts HR, Williams AC, Paraskeva $\mathrm{C}$, et al. The COX-2/PGE2 Pathway: Key Roles in the Hallmarks of Cancer and Adaptation to the Tumour Microenvironment. Carcinogenesis (2009) 30 (3):377-86. doi: 10.1093/carcin/bgp014

52. Cui N, Hu M, Khalil RA. Biochemical and Biological Attributes of Matrix Metalloproteinases. Prog Mol Biol Transl Sci (2017) 147:1-73. doi: 10.1016/ bs.pmbts.2017.02.005

53. Ahn GO, Brown JM. Matrix Metalloproteinase-9 is Required for Tumor Vasculogenesis But Not for Angiogenesis: Role of Bone Marrow-Derived Myelomonocytic Cells. Cancer Cell (2008) 13(3):193-205. doi: 10.1016/ j.ccr.2007.11.032

54. Vizoso FJ, González LO, Corte MD, Rodríguez JC, Vázquez J, Lamelas ML, et al. Study of Matrix Metalloproteinases and Their Inhibitors in Breast Cancer. Br J Cancer (2007) 96(6):903-11. doi: 10.1038/sj.bjc.6603666

55. Liu Z, Li L, Yang Z, Luo W, Li X, Yang H, et al. Increased Expression of MMP9 is Correlated With Poor Prognosis of Nasopharyngeal Carcinoma. BMC Cancer (2010) 10:270. doi: 10.1186/1471-2407-10-270

56. Mrozik KM, Blaschuk OW, Cheong CM, Zannettino ACW, Vandyke K. NCadherin in Cancer Metastasis, its Emerging Role in Haematological Malignancies and Potential as a Therapeutic Target in Cancer. BMC Cancer (2018) 18(1):939. doi: 10.1186/s12885-018-4845-0

57. Craig SEL, Brady-Kalnay SM. Cancer Cells Cut Homophilic Cell Adhesion Molecules and Run. Cancer Res (2011) 71(2):303-9. doi: 10.1158/00085472.CAN-10-2301
58. Nieman MT, Prudoff RS, Johnson KR, Wheelock MJ. N-Cadherin Promotes Motility in Human Breast Cancer Cells Regardless of Their E-Cadherin Expression. J Cell Biol (1999) 147(3):631-44. doi: 10.1083/ jcb.147.3.631

59. Ioachim E, Charchanti A, Briasoulis E, Karavasilis V, Tsanou H, Arvanitis DL, et al. Immunohistochemical Expression of Extracellular Matrix Components Tenascin, Fibronectin, Collagen Type IV and Laminin in Breast Cancer: Their Prognostic Value and Role in Tumour Invasion and Progression. Eur J Cancer (Oxford Engl 1990) (2002) 38(18):2362-70. doi: 10.1016/S0959-8049(02) 00210-1

60. Young LS, Dawson CW. Epstein-Barr Virus and Nasopharyngeal Carcinoma. Chin J Cancer (2014) 33(12):581-90. doi: 10.5732/cjc.014.10197

61. Lo YM, Chan LY, Lo KW, Leung SF, Zhang J, Chan AT, et al. Quantitative Analysis of Cell-Free Epstein-Barr Virus DNA in Plasma of Patients With Nasopharyngeal Carcinoma. Cancer Res (1999) 59(6):1188-91.

62. Lv J, Chen Y, Zhou G, Qi Z, Tan KRL, Wang H, et al. Liquid Biopsy Tracking During Sequential Chemo-Radiotherapy Identifies Distinct Prognostic Phenotypes in Nasopharyngeal Carcinoma. Nat Commun (2019) 10 (1):3941. doi: 10.1038/s41467-019-11853-y

63. Sun X-S, Chen W-H, Liu S-L, Liang Y-J, Chen Q-Y, Guo S-S, et al. Individualized Concurrent Chemotherapy by Pretreatment Plasma EpsteinBarr Viral DNA in II-III Stage Nasopharyngeal Carcinoma: A Propensity Score Matching Analysis Using a Large Cohort. Cancer Med (2019) 8 (9):4214-25. doi: 10.1002/cam4.2343

64. Yang Z, Wang J, Zhang Z, Tang F. Epstein-Barr Virus-Encoded Products Promote Circulating Tumor Cell Generation: A Novel Mechanism of Nasopharyngeal Carcinoma Metastasis. Onco Targets Ther (2019) 12:11793-804. doi: 10.2147/OTT.S235948

65. Aceto N, Bardia A, Miyamoto DT, Donaldson MC, Wittner BS, Spencer JA, et al. Circulating Tumor Cell Clusters Are Oligoclonal Precursors of Breast Cancer Metastasis. Cell (2014) 158(5):1110-22. doi: 10.1016/j.cell.2014.07.013

Conflict of Interest: The authors declare that the research was conducted in the absence of any commercial or financial relationships that could be construed as a potential conflict of interest.

Publisher's Note: All claims expressed in this article are solely those of the authors and do not necessarily represent those of their affiliated organizations, or those of the publisher, the editors and the reviewers. Any product that may be evaluated in this article, or claim that may be made by its manufacturer, is not guaranteed or endorsed by the publisher.

Copyright (๑) $2021 \mathrm{Wu}, \mathrm{Zhu}, \mathrm{Gao}$, Wang and Hu. This is an open-access article distributed under the terms of the Creative Commons Attribution License (CC BY). The use, distribution or reproduction in other forums is permitted, provided the original author(s) and the copyright owner(s) are credited and that the original publication in this journal is cited, in accordance with accepted academic practice. No use, distribution or reproduction is permitted which does not comply with these terms. 